\title{
Induction of Nonspecific Cell-Mediated Cytotoxicity: A Multisignal Event and its Cellular Regulation*
}

\author{
J. Atzpodien ${ }^{1}$, C. Bührer ${ }^{2}$, S.C. Gulati ${ }^{3}$, D. Wisniewski ${ }^{3}$, S. Ö $z^{2}$, H. Kirchner ${ }^{1}$, \\ T. Benter ${ }^{1}$, H. Poliwoda ${ }^{1}, \mathrm{~K}$. Welte ${ }^{2}$, and B. Clarkson ${ }^{3}$
}

\section{A. Introduction}

Nonspecific cytotoxic cells provide a major line of defense against tumor. While natural killer (NK) cells display spontaneous, non-MHC-restricted killing activity, both NK and non-NK lymphocytes can be induced by lymphokines to exhibit enhanced nonspecific cytotoxicity against tumor, including NK-resistant targets $[1-3]$. The latter activity is mediated by a heterogeneous cell population commonly termed lymphokine-activated killer (LAK) cells [2-4]. According to the initial concept, nonspecific LAK killing is generated via exposure to interleukin 2 (IL-2) of peripheral blood lymphocytes $[5,6]$. Most of the LAK activity appears to be mediated by NK cells stimulated with IL-2; however, recent studies suggest that induction of MHC-unrestricted lymphokine-activated killing is a more complex phenomenon requiring a multitude of cellular and noncellular signals $[2-4,7-10]$.

In our study, we approached the LAK phenomenon by asking the following

1 Department of Hematology and Oncology, Medizinische Hochschule Hannover, D-3000 Hannover 61, FRG

2 Department of Pediatric Hematology and Oncology, Medizinische Hochschule Hannover, D-3000 Hannover 61, FRG

3 Laboratory of Hematopietic Cell Kinetics, and Hematology/Lymphoma Service, Memorial Sloan-Kettering Cancer Center, New York, NY 10021, USA

* This work was supported by Deutsche Forschungsgemeinschaft grants At 12/1-1 and $\mathrm{Bu} 623 / 1-1$ and by National Institutes of Health grants $\mathrm{Ca}-20194, \mathrm{Ca}-08748$, and $\mathrm{Ca}-$ 19117 questions: (a) what are the cell types mediating LAK precursor and/or effector function? (b) What are the signals needed for the induction of nonspecific killing? Do different LAK precursor populations require different induction signals? (c) What is the regulatory role of various mononuclear cell subsets in the induction of nonspecific cytotoxicity? In order to answer these questions, we isolated and depleted NK cells, T lymphocytes, and monocytes, respectively, from fresh human peripheral blood. By culturing these cell populations under various conditions, we could define the role of both cellular and noncellular signals for the induction of $\mathrm{MHC}$-unrestricted killing in human peripheral blood.

\section{B. Methods}

Production and characterization of monoclonal antibodies (mAb) used in this study have been described elsewhere [11-18]. NK cells, T-lymphocytes, and monocytes were selectively removed and purified from peripheral blood mononuclear cells (PBMC) using techniques that have been detailed previously [19-21]. In brief, for selective removal of NK cells and $\mathrm{T}$ cells, PBMC were preincubated with mAbs N901, and OKT3 plus H65, respectively. Reactive cells were then depleted by immunoadherence to plastic plates previously coated with affinity-purified goat anti-mouse IgG. NK-depleted fractions were additionally treated with the lysomotropic agent L-leucinemethylester (LeuOMe) [22]. Monocytes were removed from fresh PBMC by adherence to plastic petri dishes. After col- 
lecting the nonadherent cells, adherent fractions were harvested by incubation with medium plus EDTA. Fractions of monocyte-depleted PBMC were purified for T-lymphocytes and for NK cells. For isolation of $\mathrm{T}$ cells, the indirect immunoadherence technique was employed using mAbs B1, B4, MY4, MY8, MO-1, and N901; nonadherent cells were subsequently treated with LeuOMe to ensure complete removal of all $\mathrm{NK}$ cells and monocytes. For separation of NK cells from peripheral blood, $\mathrm{PBMC}$ were incubated with mAbs OKT3, H65, B1, B4, MY4, and MY8; positive cells were depleted by immune rosetting with bovine red blood cells that were coated with affinity-purified goat anti-mouse IgG by $\mathrm{CrCl}_{3}$ linkage [23]. For immunofluorescence analyses [24], cells were incubated separately with $\mathrm{mAbs}$ and purified mouse IgG controls, then stained with fluorescein isothiocyanate conjugated $\mathrm{F}(\mathrm{ab})_{2}$ fragments of goat anti-mouse $\mathrm{IgG}$ and analyzed on a FACScan flow cytometer. Phenotypic analyses of isolated cell fractions revealed that all purified and depleted populations contained under $2 \%$ (i.e., no detectable) inappropriate cells. To measure nonspecific NK and LAK cytotoxicity, a standard $4-\mathrm{h}{ }^{51} \mathrm{Cr}$ release assay [25] was performed using two MHC class I negative tumor cell lines (K562, Daudi) [26, 27] as targets.

\section{Results}

I. NK Cells as Nonspecific Precursor and Effector Cells

As shown in Fig. 1, fresh thoroughly purified NK cells lysed approximately $50 \%$ of the NK-sensitive K562 cell line, as compared to $0 \%$ lysis of $\mathrm{NK}$-resistant, LAK-sensitive Daudi targets (50:1 E:T ratio). Following 5-day stimulation with recombinant $\mathrm{IL}-2(1000 \mathrm{U} / \mathrm{ml})$, cytotoxicity mediated by isolated NK cells was measured at $100 \%$ against Daudi and $16 \%$ against $\mathrm{K} 562$ (50:1 E:T ratio). When compared to unfractionated mononuclear cells, fresh unstimulated
NK cells exhibited an approximately tenfold higher non-specific killing activity, while day 5 IL-2 induced cytotoxicity was measured at equal levels in both purified NK and unseparated PBMC cultures. Thus, stringent isolation of fresh NK cells did not result in a detectable enrichment for nonspecific lymphokineactivated killing as defined by day 5 Daudi cell lysis. However, rigorous depletion of NK cells from PBMC prior to IL-2 induction completely abrogated spontaneous as well as IL-2 activated non-MHC-restricted cytotoxicity (Fig. 2).

\section{T-Lymphocytes as LAK Precursor and Effector Cells}

Figure $3 \mathrm{~A}$ gives the phenotypic analyses of highly purified T-lymphocytes that were initially depleted of NK cells and grown in short-term culture in the presence of IL-2 or IL-2 plus mitogen (PHA$\mathrm{M})$. While IL-2 by itself was unable to induce the generation of nonspecific cytotoxic cells, costimulation of IL-2 induced CD3 lymphocytes via the T3/Ti receptor antigen resulted in the generation of T-lymphocytes that expressed NK-related surface molecules (N901, H25) [17, 18] and concomitantly acquired both NK and LAK cytotoxicity (Fig. 3). As shown in Fig. 2B, when using unseparated peripheral blood mononuclear cells, a stringent removal of $T$ cells on day 0 resulted in a partial, though significant, depletion of IL-2 induced nonspecific cytolysis of Daudi. This suggested that a proportion of N901-negative T-lymphocytes represents a precursor population to MHC-unrestricted lymphokine-activated killer cells. While mediating LAK precursor functions, $\mathrm{CD}^{+} \mathrm{T}$ cells were also demonstrated to account for approximately $30 \%-50 \%$ of IL-2 induced MHC-unrestricted cytotoxicity generated in unfractionated cultures comprising NK cells, T-lymphocytes, and monocytes; evidence supporting this was provided in cell depletion experiments whereby NK cells 
Daudi

K562

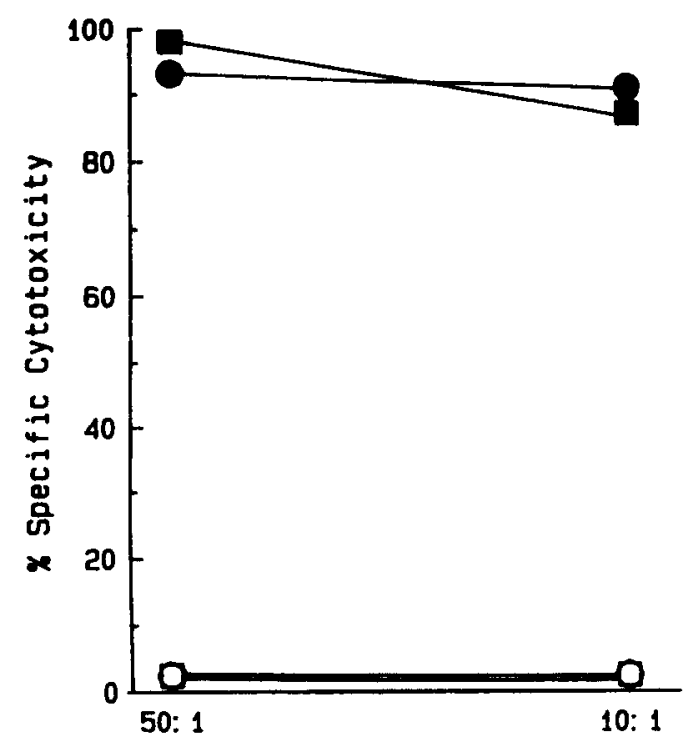

E: T Ratio

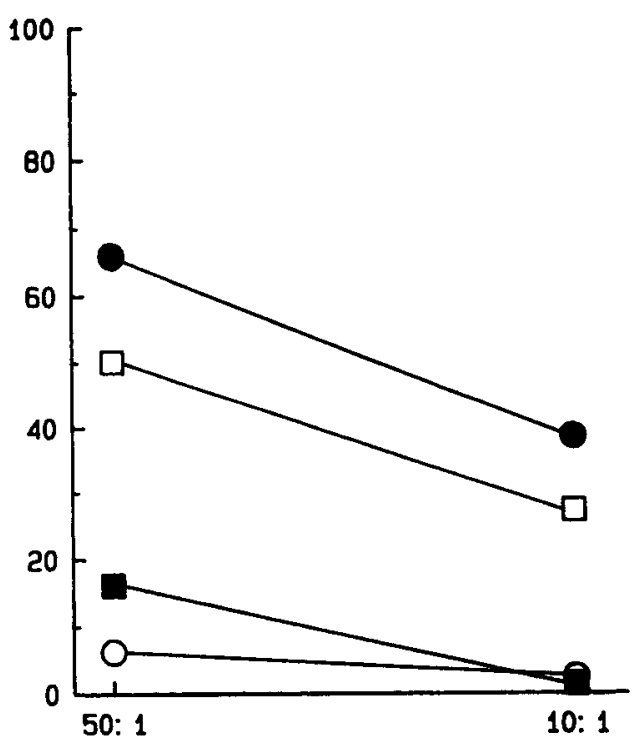

Effectors

PBMC Day 0

0

PBMC Day 5

rIL-2 1.000 U/ml

NK Cells Day 0

MK Cells Day 5

rIL-2 1.000 U/m]

E: T Ratio

Fig. 1 A, B. Comparison of cytotoxic activities against Daudi (A) and K562 (B) mediated by unseparated PBMC before and after 5-day IL-2 activation, or by purified NK cells before and after 5-day stimulation with IL-2

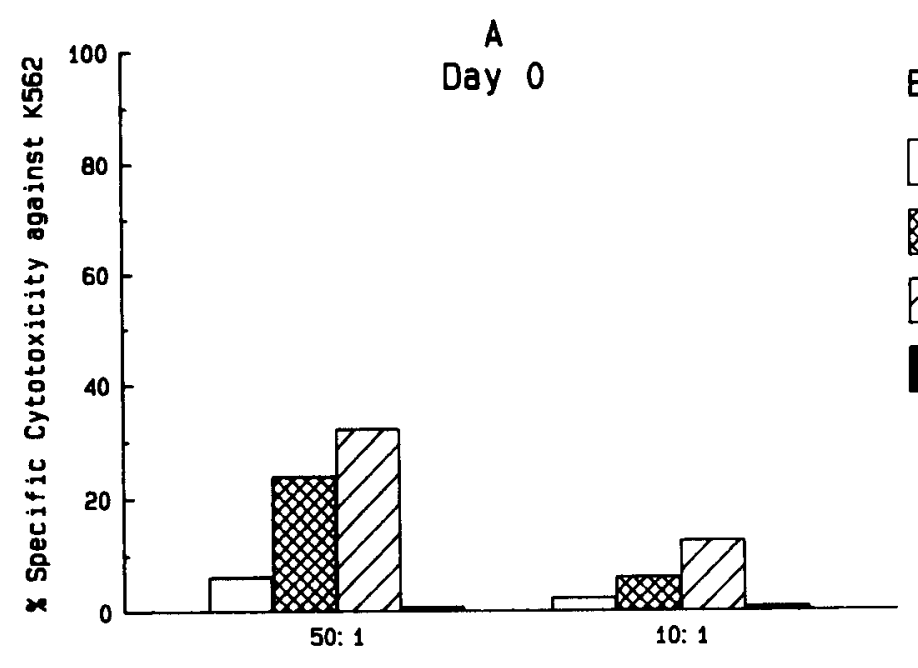

Effectors

Р日MC

Monocyte-Depleted PBMC

7 T Cell-Depleted PBMC

NK Cell-Depleted

PBMC

$B$

Day 5

$r I L-21,000 \mathrm{u} / \mathrm{ml}$

Fig. 2 A, B. Cytotoxicity before (A) and after (B) 5-day IL-2 incubation mediated by unseparated PBMC and PBMC that were depleted on day 0 of NK cells, $\mathrm{T}$ cells, or monocytes

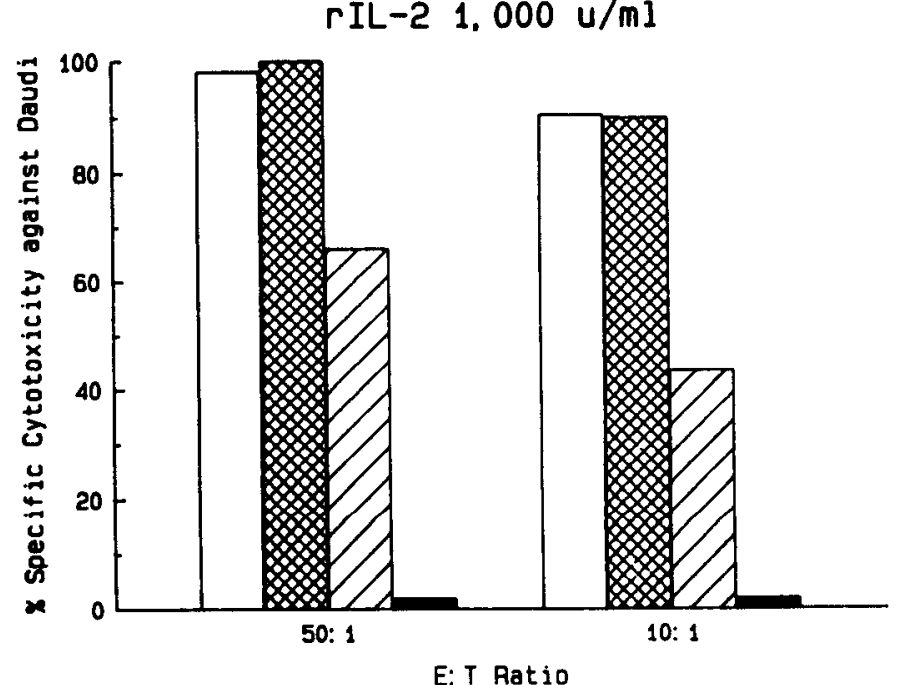




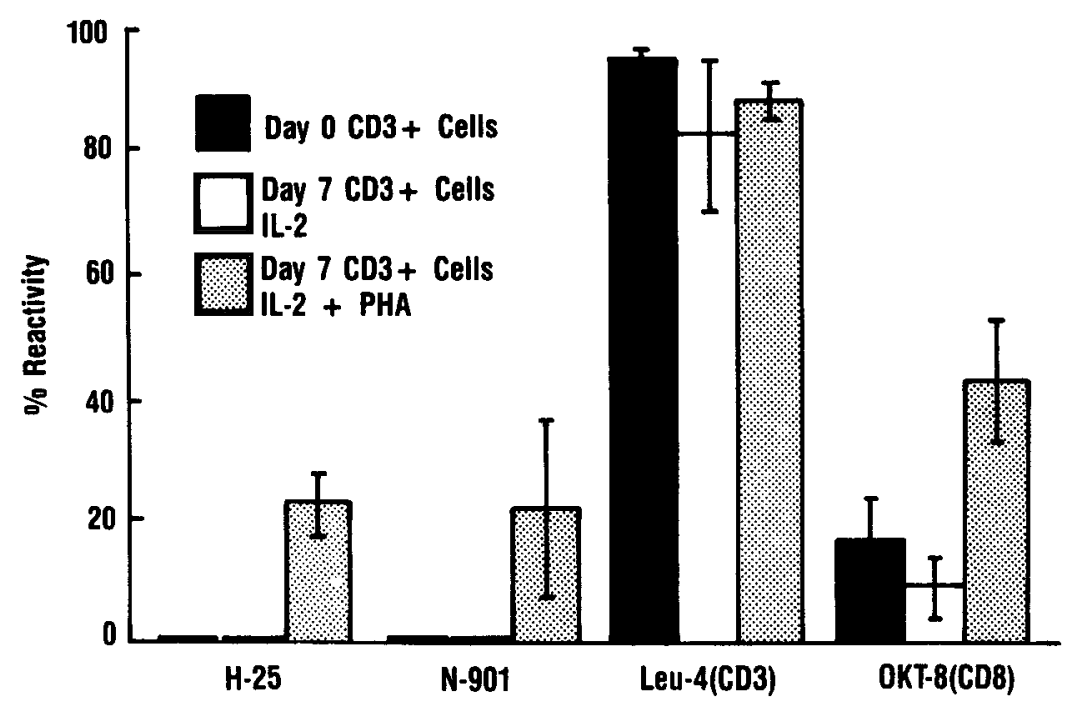

B

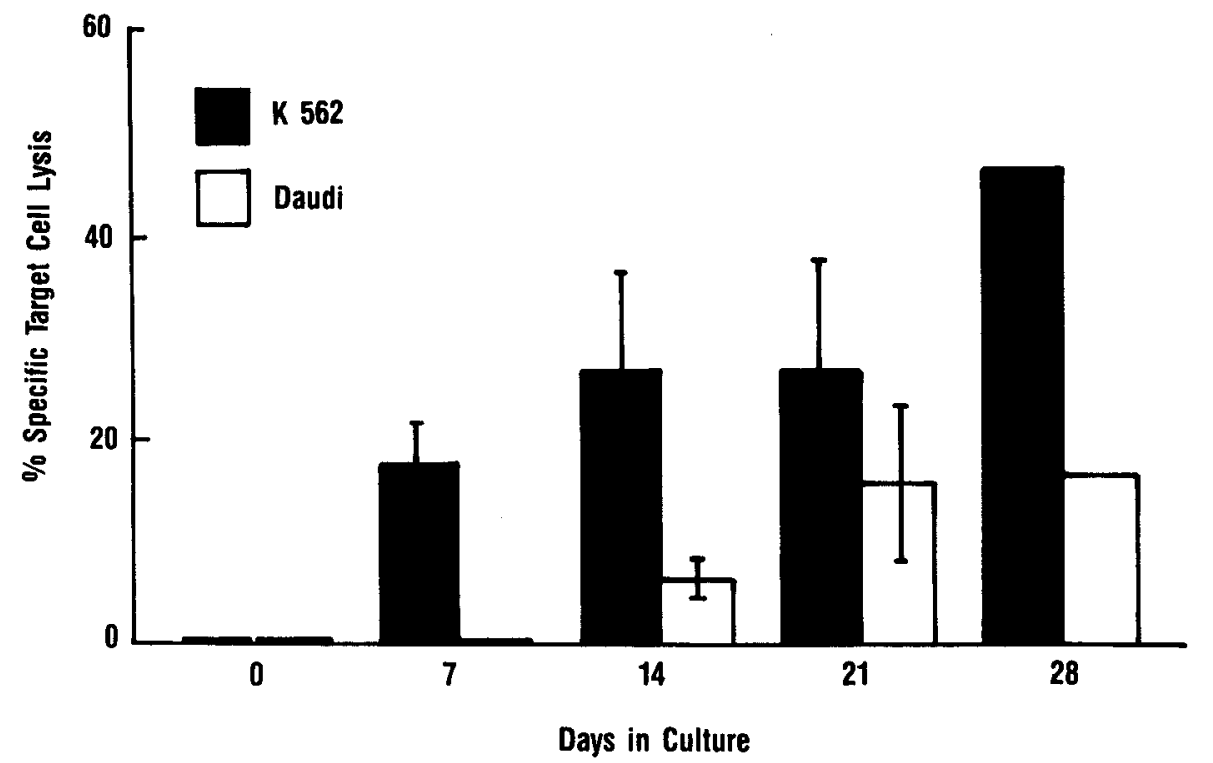

Fig. 3 A, B. Phenotypic (A) and functional (B) analyses of purified $\mathrm{CD}^{+} \mathrm{T}$ lymphocytes following induction with IL-2 in the absence (A) or presence $(\mathbf{A}$, B) of PHA mitogen

and monocytes were stringently removed from day 5 IL-2 induced cultures (Fig. 4).

III. Monocytes as Regulators of Nonspecific Cytotoxicity

PBMC, initially depleted of all detectable monocytes, showed an increased relative cytotoxicity against K562 while lymphokine-activated killing of Daudi was essentially unchanged (Fig. 2). In shortterm culture with IL-2, monocytes did not exhibit any nonspecific cytotoxicity against tumor cells. Nonetheless, proliferation of $\mathrm{MHC}$-unrestricted killer cells was augmented significantly when purified NK cells were cultured with IL-2 in the presence of autologous monocytes (Table 1). Consistently, the cumulative nonspecific cytolytic activity induced in NK cultures in response to IL-2 was increased approximately twofold with autologous monocytes present (Fig. 5). 
$\mathrm{NK}+\mathrm{T}+$ Monocytes

Day 5
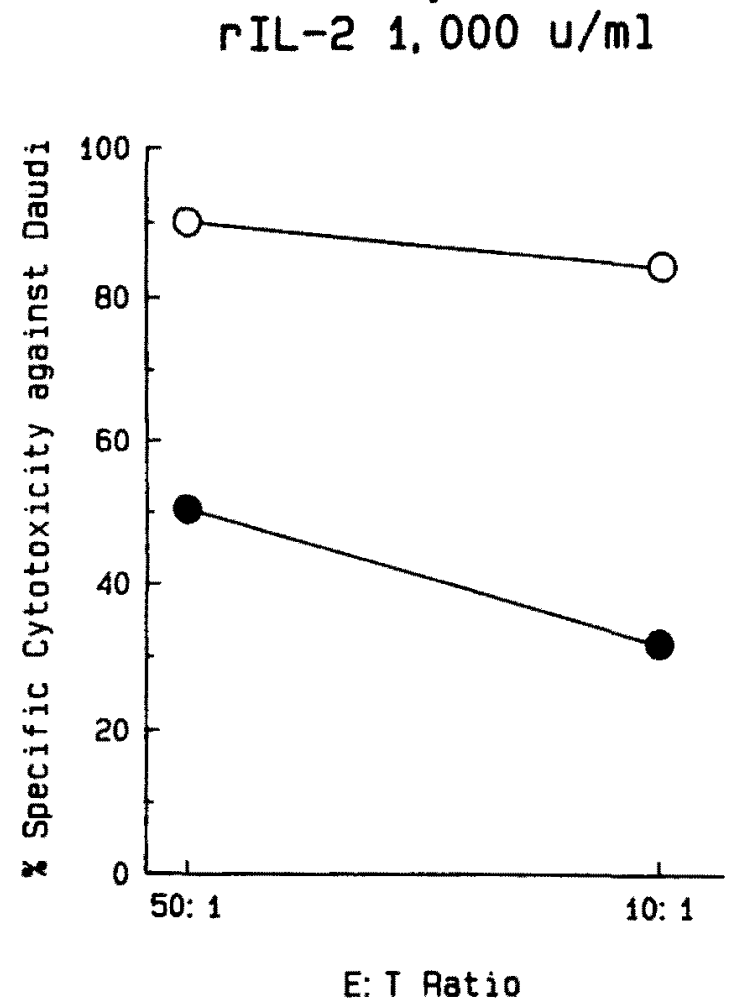

Undepleted

$\mathrm{O}$

NK/Monocyte-Depleted

(LeuOMe $40 \mathrm{mM}$ )

Fig. 4. IL-2 induced non-MHC-restricted cytotoxicity mediated by day 5 undepleted, and NK cell plus monocyte depleted effector populations that were generated in purified NK cultures in the presence of equal numbers of autologous $\mathrm{T}$ cells and monocytes

IV. T Cells and Monocytes as Coregulators of MHC-Unrestricted Lymphokine-Activated Killing

When added to NK cells on day 0 , autologous T-lymphocytes could induce an approximately fourfold increase in the absolute number of nonspecific effector cells generated upon induction with IL-2 (Table 1). While percent cytotoxicity against Daudi was essentially unchanged (data not shown), addition of T-lym-
Day 5
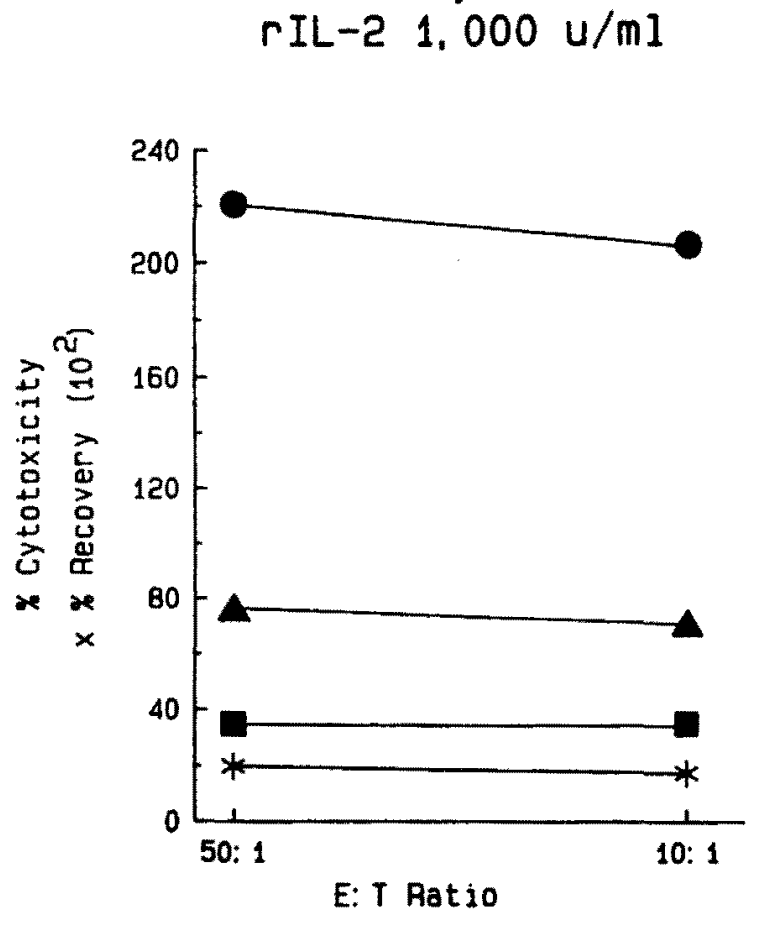

Effectors

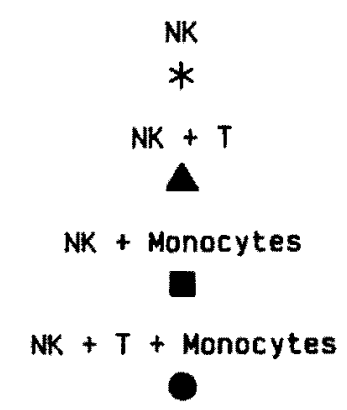

Fig. 5. Cumulative lymphokine-activated cytotoxicity (percent cytolysis $\times$ percent recovery) generated in IL-2 cultures of highly purified NK cells that were incubated alone, or in the presence of $\mathrm{T}$ cells, monocytes, or $\mathrm{T}$ cells plus monocytes

phocytes to freshly isolated NK cells resulted in a significant (i.e., more than threefold) enhancement of cumulative non-MHC-restricted killing (percent cytotoxicity $\times$ percent recovery) following 5-day IL-2 activation (Fig. 5). As shown in Table 1, costimulation of NK cells, T cells, and monocytes with IL-2 had an even more pronounced effect on the expansion of cytolytic effectors in response to cytokine. Compared to highly purified NK cells alone, approximately 15- and 
Table 1. Proliferation and cell recovery after 5-day incubation with rIL-2 of highly purified subpopulations isolated from human peripheral blood

\begin{tabular}{lcc}
\hline Peripheral blood subpopulation & $\begin{array}{l}{\left[{ }^{3} \mathrm{H}\right]-\text { Thymidine }} \\
\text { incorporation } \\
{ }^{\mathrm{a}} \\
\text { (cpm; mean } \pm 1 \text { SD) }\end{array}$ & $\begin{array}{c}\text { Cell recovery } \\
\text { b }\end{array}$ \\
\hline NK cells & $914 \pm 301$ & 20 \\
T cells & $211 \pm 107$ & 68 \\
Monocytes & $565 \pm 162$ & 10 \\
NK cells plus T cells ${ }^{c}$ & $1482 \pm 316$ & 80 \\
NK cells plus monocytes & $3162 \pm 802$ & 35 \\
T cells plus monocytes & $3466 \pm 860$ & 60 \\
NK cells plus T cells plus monocytes & $14041 \pm 2718$ & 245 \\
\hline
\end{tabular}

a $10^{4}$ cells each were pulsed with $\left[{ }^{3} \mathrm{H}\right]$-thymidine for $4 \mathrm{~h}$.

b Cell recovery as compared to day 0 was assessed by trypan blue dye exclusion test.

c After purification, the various subpopulations were admixed at equal ratios prior to rIL-2 culture.

12-fold higher levels of proliferation and cell recovery, respectively, were measured in NK cultures grown in the presence of equal numbers of $T$ cells plus monocytes (Table 1). Thus, autologous T-lymphocytes and monocytes, when added to fresh NK cells, were able to induce a dramatic (i.e., more than tenfold) increase in total nonspecific cytolytic activity generated upon 5-day stimulation with IL-2.

\section{Discussion}

Both NK and LAK cells are functionally defined by their non-MHC-restricted cytotoxicity against tumor [1-3]. In the present study, the main findings about the induction of nonspecific cell-mediated cytotoxicity in human peripheral blood are the following: (a) NK cells $\left(\mathrm{N}^{2} 1^{+} \mathrm{CD}^{-}\right)$and T-lymphocytes $\left(\mathrm{CD}^{+}{ }^{+} \mathrm{N} \mathrm{CO}^{-}\right)$can function separately as precursor cells to $\mathrm{MHC}$-unrestricted LAK cells; (b) non-NK (N901-) T cells can give rise to a subset of NK-like $\left(\mathrm{N} 901^{+}\right)$T-lymphocytes that coexpress NK (N901) and T-cell (CD3) specific antigens and concomitantly acquire NK and LAK cytotoxicity in response to IL2; (c) while in NK cells, IL-2 provides a sufficient signal for the induction of nonspecific lymphokine-activated cytotoxicity, additional activation via the T3/Ti receptor antigen is needed in order to induce non-MHC-restricted LAK activity in a proportion of mature $\mathrm{N}_{901^{-}}^{-} \mathrm{T}$ lymphocytes; (d) T cells do not only mediate but also regulate LAK precursor and effector functions whereby cumulative nonspecific cytolysis (percent cytotoxicity $\times$ recovery) is increased more than threefold in IL-2 induced NK cultures grown in the presence of $\mathrm{CD}^{+}$ cells; (e) monocytes, when coincubated with NK cells, augment the cumulative LAK activity generated in NK cultures upon stimulation with IL-2; and (f) monocytes and $T$ cells strongly synergize in enhancing the generation and activation of NK-derived MHC-unrestricted killer cells, thus producing a dramatic (i.e., more than tenfold) increase in the total nonspecific killing induced by IL-2.

While the ontogeny of IL-2 activated killer cells continues to be controversial $[2,3,8-10]$, there is pertinent evidence that the phenomenon of LAK cells defines a cellular function rather than a distinct cell type $[2-4,6]$. In this study, we show that a variety of different mononuclear cell subsets contribute to the generation and activation of non-MHC-re- 
stricted IL-2 induced killer cells. Based on the observation of various cellular and noncellular signals for the induction in human peripheral blood of nonspecific cell-mediated cytotoxicity, we propose that activation of unrestricted cytolytic cells constitutes a multisignal event tightly regulated at the cellular level. Our data indicate that application of IL-2 has both direct and indirect effects, whereby NK cells, T-lymphocytes, and monocytes may be induced to synergize in generating nonspecific killing activity in a subset of cells presenting with $\mathrm{NK}$ or NK/T cell phenotype. As to the ontogeny of NK and LAK cells, the present results also suggest that a proportion of NK-like peripheral blood mononuclear cells can be derived from mature T-lymphocytes.

Acknowledgements. We are indebted to Dr. Robert Knowles, New York, for providing $\mathrm{mAb}$ H65, and to Dr. James Griffin, Boston, for the supply of mAbs B1, B4, MY4, MY8, MO-1, and N901.

\section{References}

1. Ortaldo JR, Reynolds CW (1987) Natural killer activity: definition of a function rather than a cell type. J Immunol 138: 4545

2. Phillips JH, Lanier LL (1986) Dissection of the lymphokine activated killer phenomenon. J Exp Med 164:814-825

3. Ortaldo JR, Mason A, Overton R (1986) Lymphokine-activated killer cells. Analysis of progenitors and effectors. J Exp Med 164:1193-1205

4. Lotzová E, Herberman RB (1987) Reassessment of LAK phenomenology: a review. Nat Immun Cell Growth Regul 6:109-115

5. Lotze MT, Grimm EA, Mazumder A, Strausser JL, Rosenberg SA (1981) Lysis of fresh and cultured autologous tumor by human lymphocytes cultured in T-cell growth factor. Cancer Res 41:4420-4425

6. Grimm EA, Mazumder A, Zhang HZ, Rosenberg SA (1982) Lymphokine-activated killer cell phenomenon: lysis of natural killer resistant fresh solid tumor cells by interleukin- 2 activated autologous hu- man peripheral blood lymphocytes. J Exp Med 155:1823-1841

7. Talmadge JE, Wiltrout RH, Counts DF, Herberman RB, McDonald T, Ortaldo JR (1986) Proliferation of human peripheral blood lymphocytes induced by recombinant human interleukin-2: contribution of large granular lymphocytes and $\mathrm{T}$ lymphocytes. Cell Immunol 102:261-272

8. Roberts K, Lotze MT, Rosenberg SA (1987) Separation and functional studies of the human lymphokine-activated killer cell. Cancer Res 57:4366-4371

9. McMannis JD, Fisher RI, Creekmore SP, Braun DP, Harris JE, Ellis TM (1988) In vivo effects of recombinant IL-2. I. Isolation of circulating Leu- $19^{+}$lymphokineactivated killer effector cells from cancer patients receiving recombinant IL-2. J Immunol 140:1335-1340

10. Grossman Z, Herberman RB (1986) Natural killer cells and their relationship to T-cells: hypothesis on the role of T-cell receptor gene rearrangement on the course of adaptive differentiation. Cancer Res 46:2651-2658

11. Knowles RW (1986) Immunochemical analysis of the $T$ cell-specific antigens. In: Reinherz ER, Haynes BF, Nadler LM, Bernstein ID (eds) Human T lymphocytes. Springer, Berlin Heidelberg New York, pp 259-287

12. Kung PC, Goldstein G, Reinherz EL, Schlossman SF (1979) Monoclonal antibodies defining distinctive human $\mathrm{T}$ cell surface antigens. Science 206:347-349

13. Stashenko $P$, Nadler LM, Hardy $R$, Schlossman SF (1980) Characterization of a human B lymphocyte-specific antigen. J Immunol 125:1678-1685

14. Nadler LM, Anderson KL, Marti G, Bates M, Park E, Daley JF, Schlossman SF (1983) B4, a human B lymphocyte-associated antigen expressed on normal, mitogen-activated, and malignant $\mathrm{B}$ lymphocytes. J Immunol 131:244-250

15. Griffin JD, Ritz J, Nadler LM, Schlossman SF (1981) Expression of myeloid differentiation antigens on normal and malignant myeloid cells. J Clin Invest 68:932-941

16. Todd RF, Nadler LM, Schlossman SF (1981) Antigens on human monocytes by monoclonal antibodies. J Immunol 126:1435-1442

17. Griffin JD, Hercend T, Beveridge R, Schlossman SF (1983) Characterization of 
an antigen expressed by human natural killer cells. J Immunol 130:2947-2951

18. Bai Y, Beverly PCL, Knowles RW, Bodmer WF (1983) Two monoclonal antibodies identifying a subset of human peripheral blood mononuclear cells with NK and $\mathrm{K}$ cell activity. Eur $\mathrm{J}$ Immunol 13:521-527

19. Wysocki LJ, Sato VL (1978) Panning for lymphocytes: a method for cell selection. Proc Natl Acad Sci USA 75:2844-2848

20. Wisniewski D, Strife A, Wachter $M$, Clarkson B (1985) Regulation of human peripheral blood erythroid burst-forming unit growth by $\mathrm{T}$ lymphocytes and $\mathrm{T}$ lymphocyte subpopulations defined by OKT4 and OKT8 monoclonal antibodies. Blood 65:456-463

21. Atzpodien J, Gulati SC, Shimazaki C, Bührer C, Öz S, Kwon JH, Kolitz JE, Clarkson BD (1988) Ewing's sarcoma: exvivo sensitivity towards natural (NK) and lymphokine-activated (LAK) killing. Oncology 45:437-443

22. Thiele DL, Lipsky PE (1986) Leu-leu-ome sensitivity of human activated killer cells: delineation of a distinct class of cytotoxic
T lymphocytes capable of lysing tumor targets. J Immunol 137:1399-1406

23. Goding JM (1976) The chromic chloride method of coupling antigens to erythrocyte: definition of some important parameters. J Immunol Methods 10:61 66

24. Herzenberg LA, Herzenberg LA (1977) Analysis and separation using the fluorescence activated cell sorten (FACS) In: Weir EM (ed) Handbook of experimental immunology. Blackwell, Oxford, pp 22.1 $-22.21$

25. Pross HF, Maroun JA (1984) The standardization of NK cell assays for use in studies of biological response modifiers. $J$ Immunol Methods 68:235-249

26. Lozzio CB, Lozzio BB (1975) Human chronic myelogenous leukemia cell line with positive Philadelphia chromosome. Blood 45:321-334

27. Klein E, Klein G, Nadkarni JS, Nadkarni JJ, Wigzell H, Clifford P (1968) Surface IgM-kappa specificity on a Burkitt lymphoma cell in vivo and in derived culture lines. Cancer Res 28:1300-1310 